\title{
LA TRADICIÓ GREGA DEL CULTE DE CEBRIÀ D'ANTIOQUIA I SANTA JUSTINA A CATALUNYA
}

\author{
MONTSERRAT CAMPS GASET \\ Universitat de Barcelona \\ mcamps@ub.edu \\ ORCID: 0000-0001-8486-6036
}

RESUM

El culte de Cebrià d'Antioquia i santa Justina té l'origen en un text grec apòcrif del segle IV i des dels inicis s'ha confós amb la biografia de sant Cebrià, bisbe de Cartago. A Catalunya hi ha diverses esglésies antigues dedicades a un dels dos, i no sempre queda clara la diferència. Alguns dels goigs cantats en honor del sant donen testimoni de l'antiga llegenda oriental i de la confusió amb el bisbe. Aquí es presenta una proposta d'identificació d'una màrtir desconeguda que apareix al retaule de sant Cebrià de Cabanyes, del segle XV.

PARAULES CLAU: Cebrià d'Antioquia, hagiografia grega, Sant Cebrià de Cabanyes, Santa Justina, pintura gòtica, màgia grega.

\section{THE GREEK TRADITION OF THE CULT IN CATALONIA OF CYPRIAN FROM ANTIOQUIA AND SAINT JUSTINE.}

\section{ABSTRACT}

The cult of Cyprian of Antioch and Saint Justine has its origins in a Greek apocryphal text from the $4^{\text {th }}$ century, and has been merged with the biography of Saint Cyprian Bishop of Carthage. In Catalonia, several old churches are dedicated to either one or the other Cyprian and it is not always clear to which of the two. Some of the anthems sung in honour of the Saint bear witness to the ancient Eastern legend and its confusion with the biography of the African Bishop. A proposal is made here concerning the identification of an unknown female martyr in the altar painting of Sant Cebrià de Cabanyes, from the $15^{\text {th }}$ century.

KEYWORDS: Cyprian of Antioch, Greek hagiography, Sant Cebrià de Cabanyes, Saint Justine, Gothic paintings, Greek magic.

\section{ELS APÒCRIFS GRECS SOBRE CEBRIÀ I JUSTINA D'ANTIOQUIA I LA TRADICIÓ OCCIDENTAL}

Tradicionalment la figura de santa Justina ha estat vinculada a la figura de Cebrià, suposat bisbe d'Antioquia, considerat sant per l'església ortodoxa. La relació entre tots dos es basa en una llegenda que té les arrels en unes narracions gregues anònimes del segle IV, considerades per la filologia alemanya de finals 
del segle XIX com un antecedent remot de la figura de Faust. ${ }^{1}$ Si bé és discutible que el relat grec sigui un avantpassat directe del nigromant alemany, sí que és cert que es tracta del primer cop que, en literatura cristiana, trobem un tracte amb el diable per tal d'aconseguir coneixement. El relat grec en prosa sobre Cebrià d'Antioquia té tres parts, de transmissió textual independent: La Conversió o els Fets de Cebrià i Justina, la Confessió o Penitència, i el Martiri. La Confessió és la narració més pintoresca i rica en detalls màgics i sobrenaturals, i fou prohibida pel decret gelasià, sense ni merèixer l'atribut de narració pietosa o edificant que tenen alguns texts apòcrifs.

És possible que hi hagués tres màrtirs orientals, Cebrià, Justina i Teoctist, les relíquies dels quals foren traslladades des de Nicomèdia a Roma al s. IV (una possible data de martiri a Damasc és el 304), en un moment en què les relíquies començaven a tenir importància. ${ }^{2} \mathrm{Al}$ marge, però, de la difícil documentació històrica d'aquests personatges, tot el relat sobre Cebrià és ficció. No hi ha cap testimoni històric fiable del fet que hi hagués a Antioquia un bisbe de nom Cebrià, i encara menys que fos un màgic convertit.

Els Fets expliquen la conversió de Justina en sentir predicar un deixeble de Pau, l'enamorament del jove pagà Aglaïdas, que contracta Cebrià perquè li aconsegueixi els favors de la noia, no cal dir que debades, i la conversió final de Cebrià al cristianisme, per acabar com a bisbe d'Antioquia. La Passió o Martiri explica com Cebrià i Justina són detinguts, a causa dels seus miracles, i portats a Damasc, on són torturats i llançats a una caldera bullent, però sobreviuen als turments i són enviats a Nicomèdia, on Dioclecià els condemna a ser decapitats. Al cap de sis dies els cossos, junt amb el de Teoctist, un home decapitat amb ells per haver saludat Cebrià, són enviats a Roma on reben sepultura.

En canvi, la Confessió sembla un text amb autonomia pròpia, de transmissió textual independent, i que repeteix episodis coneguts pels Fets, però que insisteix molt més en la joventut del màgic. Cebrià és l'home pagà per antonomàsia. El text, escrit en primera persona, recorre la infantesa de Cebrià i el seu aprenentatge com a bruixot, que inclou tots els possibles estudis a casa dels millors experts. ${ }^{3}$ S'inicia a Egipte, lloc del coneixement esotèric per excel-lència; investiga els misteris dels caldeus, o sigui, dels tradicionals representants de la idolatria i la màgia i, finalment, aconsegueix el punt suprem de les arts negres amb una trobada amb el Diable en persona, el qual li confereix autoritat com a bruixot. El mag Cebrià obre un negoci professional a Antioquia, on Aglaïdas li demana que li procuri l'amor de Justina. Primer intenta seduir Justina per al seu client, i després se n'enamora ell i es dedica a aconseguir-la per a ell mateix. Un darrere

\footnotetext{
1 Zahn (1882), que edità el text, el considerava antecedent del Volksbuch alemany, idea seguida per Radermacher (1927), el qual hi aportà més paral·lels grecs. El recull clàssic (en anglès) dels suposats antecedents del Faust es troba a Palmer-More (1936).

2 Bailey (2009: 3).

${ }^{3}$ Nilsson (1947) i Camps-Gaset (2019).
} 
l'altre, hi envia esperits (dimonis) i, finalment, un drac. Com que Justina descobreix cada vegada que es tracta d'un engany malèfic, Cebrià demana al Diable que hi vagi en persona, però aquest també fracassa, perquè la noia li fa el senyal de la creu. Cebrià es compromet amb el Diable a canvi que aquest li expliqui quina és aquesta màgia més poderosa capaç de vèncer el diable mateix, i quan aquest li explica que és la creu, el mag renuncia al diable per dedicar-se al Crist. Llavors, Cebrià fa confessió pública de tot el mal que ha fet: sacrificis d'infants, assassinat de dones prenyades, estrangers decapitats, actes de pederàstia, naufragis de vaixells, destrucció d'esglésies, burles de la pregària. El prevere Eusebi accepta la confessió de Cebrià i li diu que el Crist l'acollirà, perquè no solament era ignorant, sinó que era mogut pel dimoni. Eusebi enumera un munt d'exemples de figures bíbliques que abandonaren el Diable i foren acollides per Déu. Cebrià s'afegeix a la comunitat cristiana d'Antioquia, crema els llibres màgics i es fa batejar.

Zahn, va postular que els Fets i el Martiri provenen del mateix autor, però no la Confessió, tot i que el rerefons argumental és el mateix, i que és possible que la Confessió sigui una mica més tardana. Sabattini ${ }^{4}$ proposa, en canvi, que els Fets i la Confessió siguin anteriors al 379, mentre que el Martiri seria redactat entre el 379 i el 440, data del poema d'Eudòcia, la dona de Teodosi II, la qual coneix sens dubte les tres peces esmentades. ${ }^{5}$ La raó de la data és la confusió que fa Gregori de Nazianz entre la llegenda de Cebrià d'Antioquia i la figura de Cebrià, bisbe de Cartago, molt cèlebre ja a l'època. Cebrià de Cartago mor el 258, els suposats màrtirs de Nicomèdia el 304, Gregori escriu el panegíric de Cebrià (discurs 24) el 379, i Eudòcia el poema a la primera meitat del s. V.

La Confessió depèn dels Fets, però hi afegeix elements nous que potser provenen d'una altra font perduda o s'adrecen a un públic diferent. L'exemplaritat de l'argument va acompanyada d'unes llargues digressions sobre elements molt pintorescs que devien ser familiars en la cultura popular i que mereixen un altre estudi.

Gregori de Nazianz segur que coneix els Fets i la Confessió, de la manera com en parla. Potser és el primer que confon els dos Cebrià, o potser es fa ressò d'una tradició oral que ja els barrejava, cosa probable, perquè no creiem que la confusió provingui de la precipitació. ${ }^{6}$ No sembla que hi hagi base històrica per

\footnotetext{
4 Sabattini (1973: 181). No ens sembla gaire probable una datació tan tardana del Martiri.

${ }^{5}$ Eudòcia escrigué un poema en dístics, parcialment conservat, sobre Cebrià i Justina, seguint els tres texts aquí esmentats. Hi ha una llarga bibliografia sobre aquest poema de l'emperadriu; pel que fa a la data, cf. Livrea (1998).

${ }^{6}$ Sobre aquest discurs, cf. Delehaye (1931). Per molt precipitada que fos la redacció del discurs en memòria de Cebrià de Cartago, Gregori de Nazianz tenia vasta cultura retòrica, i no hem d'oblidar que en aquella època escriure no era un fet casual improvisat, sinó que requeria una bona dosi de consciència i maduració. No es posa per escrit qualsevol cosa, sinó allò que hom vol escriure. O bé Gregori tenia motius per atribuir la llegenda al bisbe cartaginès, o bé ho havia
} 
postular un Cebrià bisbe d'Antioquia ni la seva relació amb Justina, en canvi, la figura del bisbe cartaginès es va escampar ràpidament per Orient i Occident, com a escriptor cristià i com a màrtir. ${ }^{7}$ Tant pot ser que Gregori fos el primer autor de la contaminatio com que seguís una tradició oral en què s'atribuís al cartaginès el protagonisme de la pseudonovel·la, que devia tenir una gran difusió a l'època. $\mathrm{Si}$, a Orient, Gregori entrellaça la llegenda del bruixot amb l'elogi del bisbe de Cartago, a Occident, Prudenci també atribueix un passat obscur al bisbe cartaginès, però no és gens clar que conegui cap dels texts esmentats. Prudenci ${ }^{8}$ descriu Cebrià de Cartago, amb una referència molt vaga a un passat nigromàntic, sense cap al·lusió a Justina ni cap detall concret que permeti pensar que confon efectivament els dos personatges. Per l'època, però, és molt proper a la redacció del text grec, i potser existia una tradició oral que atribuïa al bisbe de Cartago una història obscura, tot i que els versos es poden explicar per al-lusions literàries més que per referències a altres relats sobre el bisbe cartaginès. ${ }^{9}$ Tampoc la Vita S. Cypriani de Ponci no té cap rastre de la història antioquena.

A Occident, el Martyrologium de Beda el Venerable, del s. VIII, esmenta sant Cebrià, bisbe cartaginès martiritzat amb sant Corneli, el dia 16 de setembre (data de celebració en el santoral) i, en una altra banda, també santa Justina i sant Cebrià, amb la història del martiri, el dia 26 de setembre (dia en què en el santoral se celebra habitualment santa Justina, junt amb sant Cebrià d'Antioquia). Beda, doncs, separa els dos sants, que esdevenen màrtirs sota autoritats romanes diferents.

El Pasionario Hispànico, que es considera format al segle VII, relata el martiri de sant Cebrià de Cartago, sense cap al-lusió ni a Antioquia ni a la vida o mort del Cebrià oriental. ${ }^{10}$ Prudenci devia influir força en el Pasionario, però en el relat sobre Cebrià no hi ha cap rastre de les al·lusions màgiques que fa l'autor llatí, cosa que confirmaria la intenció literària del text de Prudenci i no tant la tradició d'una suposada biografia obscura del cartaginès.

La Llegenda Àuria del s. XIII presenta la narració de la vida de santa Justina d'acord amb els Fets, però posant l'èmfasi (com el text grec) en la conversió de la santa i, tot i que explica la conversió de Cebrià, no el considera sant. En un altre

sentit explicar sempre així i el text grec era prou popular perquè el públic que escoltava el discurs no se n'estranyés.

7 Veronese (2006: 79-81).

8 Peristephanon XIII 21-27: «unus erat iuuenum doctissimus artibus sinistris: /fraude pudicitiam perfringere, nil sacrum putare,/saepe etiam magicum cantamen inire per sepulcra,/quo geniale tori ius solueret aestuante nupta.» De Cebrià d'Antioquia no es diu que anés als sepulcres ni que tingués relació amb cap dona casada. Les arts màgiques eren freqüents a la Roma imperial. 9 Petruccione (1990). La vida del bisbe de Cartago fou prou polèmica perquè se li atribuís un passat discutible des del punt de vista de l'ortodòxia, i això podia afavorir la confusió.

${ }^{10}$ Fábrega (1953, II: 336-338), si bé Fábrega (1953, I: 189 i 235) distingeix entre el culte molt antic (del s. v) de Cebrià de Cartago i les passions de Justina i Cebrià, posteriors al s. VIII. 
capítol, relata la vida de sant Cebrià de Cartago junt amb sant Corneli. ${ }^{11}$ Una cosa semblant es pot dir del dominic del s. XIII Jean de Mailly, el qual refereix la vida de sant Cebrià de Cartago i, a continuació, la de santa Justina, en relació amb la qual explica les aventures de Cebrià, convertit i màrtir, però sense anomenar-lo sant. ${ }^{12}$ Sembla que Mailly ha llegit la Confessió, perquè en fa un resum al final. El Flos Sanctorum castellà del segle XVIII relata sant Corneli (p. 623), sant Cebrià de Cartago (p. 624) i, més endavant, santa Justina (p. 641) junt amb sant Cebrià $\mathrm{d}$ 'Antioquia, tots dos màrtirs, segons el relat conegut del Martiri, i indica explícitament que Gregori de Nazianz es va equivocar en confondre les vides dels dos bisbes. Cita, com a fonts, Simeó Metafrastés ${ }^{13}$ i Beda.

La tradició occidental distingeix, doncs, entre Cebrià de Cartago (vinculat o no amb Corneli), d'una banda, i Justina, màrtir, de l'altra, la qual, al seu torn, va acompanyada d'un altre Cebrià, primer bruixot i després bisbe d'Antioquia i també martiritzat amb ella.

\section{EL CULTE DE CEBRIÀ I JUSTINA A CATALUNYA}

A Catalunya, com a la resta d'Espanya, trobem moltes esglésies o ermites dedicades a sant Cebrià de Cartago, per la popularitat i antiguitat del sant cartaginès, el culte del qual es va estendre molt aviat a la península. ${ }^{14}$

Ara bé, algunes esglésies catalanes estan dedicades específicament a sant Cebrià i santa Justina, cosa que significa que a l'origen de la invocació hi ha la figura del bruixot més que la del bisbe cartaginès. Les hem classificades de la manera següent, $\mathrm{i}$ hem resseguit, fins allà on ens ha estat possible, la tradició dels goigs de cada indret, tenint en compte que els goigs acostumen referir la vida del sant $i$, per tant, es fan ressò de les fonts hagiogràfiques.

\subsection{Esglésies dedicades inequívocament a sant Cebrià d'Antioquia i santa Justina}

a) Ermita de sant Cebrià i santa Justina a Horta, Barcelona, amb goigs que expliquen la llegenda del bruixot. ${ }^{15}$

\footnotetext{
${ }^{11}$ Legenda Aurea 133 i 138, edició de Maggioni (1998: 948-9; 971-6). Probablement la Llegenda Àuria és la font que fa servir Calderón de la Barca per escriure la seva obra El mágico prodigioso, sobre el bruixot Cebrià.

12 Mailly cap. 138, 139 i 148, edició de Maggioni (2013: 384-5; 403).

${ }_{13}$ L'edició del Flos Sanctorum castellà consultada és impresa a Barcelona el 1794. Simeó Metafrastés, autor bizantí del s. IX, reprodueix gairebé sencers els Fets i el Martiri de Justina i Cebrià, el 26 de setembre.

${ }^{14}$ Blázquez (1986), Díaz y Díaz (1998), Ramos Lissón (2012).

${ }^{15}$ Es poden trobar a: http://bibliogoigs.blogspot.com/2011/09/goigs-de-sant-cebria-i-santa-just ina-la.html [data de consulta 20 d'octubre de 2019].
} 
b) Sant Cebrià i santa Justina al castell de Fluvià, a sant Esteve de Palautordera. El text dels goigs és el mateix de l'ermita d'Horta. ${ }^{16}$

c) Sant Cebrià de Mollet de Peralada o d'Empordà. L'església fou una antiga possessió del monestir de Vilabertran, des del 1093. El retaule de sant Cebrià, del s. XVI, presenta santa Justina a la dreta, junt amb sant Miquel i sant Nicolau. Els goigs d'aquesta església relaten gairebé tota la llegenda de Cebrià d'Antioquia.

\subsection{Altres esglésies dedicades a sant Cebrià, o amb retaules o capelles}

Es tracta probablement del bisbe de Cartago (la relació no és exhaustiva):

a) Sant Cebrià dels Alls, a Cruilles (Baix Empordà).

b) Sant Cebrià d'Aiguallonga, a Valldoreix (Vallès), consagrada el 1047.

c) Sant Cebrià de Vallalta (Maresme), consagrada el 1019, amb goigs sobre el sant africà. ${ }^{17}$

d) Sant Cebrià de Tiana (Maresme), consagrada el 1100.

e) Santa Margarida de Cabrera de Mar (Maresme), desapareguda, però dedicada primer a Sant Cebrià, segons document del segle XI. ${ }^{18}$

f) Sant Cebrià de Cartago a Flaçà (Gironès), amb goigs sobre la vida del sant africà. ${ }^{19}$

g) Sant Cebrià de la Móra (Vallès Oriental), amb goigs sobre la vida del sant africà. ${ }^{20}$

h) Sant Cebrià d'Esponellà (Pla de l'Estany), del segle $\mathrm{X}$, amb goigs sobre la vida del sant africà.

i) Sant Cebrià de Vilafant (Alt Empordà), documentada l'any 1119. ${ }^{21}$

j) Sant Cebrià de Torroella (Baix Empordà), del segle XII.

k) Sant Cebrià de Lledó (Baix Empordà), del segle XI. ${ }^{22}$

\footnotetext{
16 Disponible a: http://bibliogoigs.blogspot.com/search/label/Fluvi\%C3\%A0 [data de consulta 20 d'octubre de 2019].

17 Disponible a: https://algunsgoigs.blogspot.com/2015/06/goigs-sant-cebria-sant-cebria-de.h tml [data de consulta 20 d'octubre de 2019].

18 Ribas (1985).

19 Disponible a: https://algunsgoigs.blogspot.com/2016/07/goigs-sant-cebria-flaca-girones-giro na.html [data de consulta 20 d'octubre de 2019].

20 Disponible a: https://algunsgoigs.blogspot.com/2015/03/goigs-sant-cebria-la-mora-tagam anent.html [data de consulta 20 d'octubre de 2019]. Els goigs referits aquí provenen d'aquestes fonts d'internet o de col·lecció particular.

21 Segons el mateix poble de Vilafant, cf. http://www.elpuntavui.cat/cultura/article/19cultura/1679277-commemoren-els-900-anys-de-sant-cebria-de-vilafant.html. Segons la Planificació de l'espai fluvial de la conca de la Muga, de la Generalitat de Catalunya, l'església s'esmenta el 1193.

22 Segons les restes conservades, cf. Badia (1983: 62).
} 
1) Ermita de sant Cebrià de Cabanyes, a Sant Fost de Campsentelles, amb un retaule dedicat a St. Cebrià de Cartago, que tractarem més endavant. L'església fou consagrada el 1193. ${ }^{23}$

m) Sant Cebrià de Rosselló (Sallix), del segle IX; Monestir de Sant Cebrià de Cubera, del segle IX, al bisbat d'Elna, entre moltes d'altres a la Catalunya Nord. ${ }^{24}$

Els goigs que es canten o cantaven a cada ermita relaten la vida del sant cartaginès, amb esment explícit a Cartago i cap referència a Antioquia, però n'hi ha tres que esmenten un passat obscur vinculat amb el dimoni, i són: els de Sant Cebrià dels Alls, que esmenten l'adoració als ídols, cosa que pot ser simplement una al·lusió al paganisme; els de sant Cebrià de Vallalta, que esmenta els «errors de joventut» del sant, i els de Sant Cebrià de la Mora, amb una estrofa que esmenta «el culte de l'infernal».

\subsection{Esglésies dedicades a sant Cebrià i sant Corneli}

En aquest cas, la vida de Corneli està directament relacionada amb Cebrià de Cartago, sense cap al·lusió al personatge d'Antioquia:

a) Sant Cebrià i sant Corneli a Ordino.

b) Sant Corneli i sant Cebrià de Lleret (Pallars Sobirà).

c) Sant Corneli i sant Cebrià a Cardedeu.

d) Sant Corneli i sant Cebrià al Mas Novelles d'Avall, antic terme de Tavertet, documentada al segle XIII. ${ }^{25}$

Convé tenir en compte que, al segle XI, es traslladen a Piacenza, a Itàlia, les relíquies de Justina, junt amb les de Cebrià i Teoctist, i que aquest és l'origen de la tradició de santa Justina de Pàdua. ${ }^{26}$ En aquest mateix segle apareixen les esglésies romàniques dedicades a Cebrià i Justina a la Catalunya vella, o sigui, abans de la Llegenda Àuria (la qual considera Justina santa, però no Cebrià).

Per tant, en les ermites i esglésies referides, allà on hi ha invocació a Justina, apareix una llegenda negra de Cebrià, basada en els Fets o en la Confessió, considerat bisbe d'Antioquia i de vegades sant. Hi ha tres casos molt evidents, el de l'ermita d'Horta, el del Castell de Fluvià i el de Mollet d'Empordà, on l'església és dedicada només a sant Cebrià, però la documentació conservada sobre el retaule, del s. XVI, i també els goigs, esmenten Justina i la història del bruixot.

En canvi, allà on es veneren Cebrià i Corneli la referència és, sense dubte, per al bisbe de Cartago, mentre que allà on hi ha només advocació a sant Cebrià

\footnotetext{
${ }^{23}$ Ordeig (1991: 378-379).

24 Zaragoza (1977: 84).

25 Per a aquesta relació hem consultat, entre d'altres, Zaragoza (1977), Ordeig (1991), i Monsalvatje (1908).

${ }^{26}$ Canetti (2009).
} 
i es tracta d'una fundació antiga, es tracta amb molta probabilitat de sant Cebrià de Cartago, atesa la particular vinculació amb la península que ja tingué en vida, però queda el dubte de si hi havia cap rastre de la llegenda oriental o no. No és gens clar que el discurs de Gregori de Nazianz que confonia els dos Cebrià arribés a Occident de manera generalitzada, almenys en un primer moment, atès que els martirologis esmentats diferencien els dos personatges, però, en canvi, és molt possible que hi hagués una tradició oral que els unís o almenys els relacionés, a partir de la poc aconsellable però molt popular Confessió, en traducció llatina, de manera que, allà on hi ha Justina, el referent últim i obligat és Cebrià d'Antioquia, mentre que allà on Cebrià és venerat tot sol hi pot haver la tradició d'un passat de joventut poc exemplar, representat pels ídols, tot i que l'èmfasi rau en els escrits, la teologia i l'activitat pública del ben documentat bisbe cartaginès. L'imaginari popular pot atribuir fàcilment a un mateix nom llegendes diferents. L'església catòlica va eliminar Cebrià d'Antioquia del santoral el 1969, per considerar-lo un sant llegendari que no va existir mai. A la tradició oriental se'l continua venerant com a sant. A Occident, la festa de sant Cebrià de Cartago se celebra el dia 16 de setembre (amb sant Corneli), mentre que santa Justina se celebra el 26 de setembre i, de vegades encara amb sant Cebrià d'Antioquia. En aquesta data se celebren les festes majors de les ermites esmentades.

D'aquestes, la més cèlebre és encara l'ermita d'Horta, dedicada a sant Cebrià i santa Justina, i present en l'imaginari popular fins avui mateix. Joan Amades $^{27}$ explica que Cebrià era de Barcelona, que tots els fets que explica la Confessió tingueren lloc a Barcelona, i que l'ermita s'erigí allà on hi havia una casa de la família de Justina. Fins i tot acaba fent bisbe de Barcelona el mateix Cebrià (no cal dir que sense cap testimoni històric). Sembla més creible la fama de l'ermita a l'Edat Mitjana, fins al punt que es diu que fou visitada per sant Francesc d'Assís i també per sant Ignasi de Loiola. ${ }^{28}$ Amades ens diu també que els calderers veneraven els dos sants perquè van sofrir el martiri en una caldera bullent. La imatge del martiri a la caldera i la de la crema dels llibres màgics de Cebrià són les dues més reproduïdes en els goigs i en les estampes vuitcentistes que es refereixen a aquests personatges, i són signe inequívoc que es coneixien almenys els Fets i el Martiri.

La confusió, doncs, entre un i altre Cebrià s'ha transmès potser per via oral, pel coneixement de la traducció llatina dels Fets (i de la Confessió, vetada pel decret gelasià, però no pas per això menys llegida), que devia influir potser en Prudenci, però sobretot en la pregària i en la tradició popular, la qual - fora de l'ortodòxia eclesial - ha continuat atribuint a Cebrià la protecció de la màgia i l'acció sobre les forces del mal ${ }^{29}$ i ha transmès la biografia poc exemplar del

\footnotetext{
27 Amades (1983: 205-206) i (1984: 89-91).

${ }_{28}$ Madurell (1948: 162) i (1960).

29 Per la seva complexitat, deixem per a una altra ocasió la tradició de les Orationes pseudocypriani, en la versió litúrgica i en la versió popular prohibida.
} 
bruixot a través de la literatura de fil i canya. ${ }^{30}$ Des de la seva conversió, Cebrià d'Antioquia, sant o no, fou considerat el protector per excel-lència contra les males arts del dimoni, perquè era el millor coneixedor de les arts màgiques, aquest cop des del bàndol celestial. ${ }^{31}$

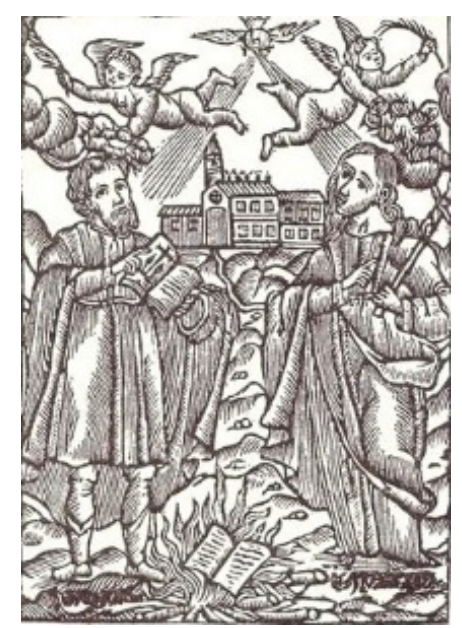

1. Xilografia dels goigs de l'ermita d'Horta amb la crema de llibres

\section{El retaule de Sant Cebrià de Cabanyes}

Com a conseqüència d'aquest recorregut per les tradicions, adés confoses i adés separades, de Cebrià de Cartago i Cebrià d'Antioquia, fem una proposta en relació amb el retaule gòtic de sant Cebrià de Cabanyes. A la predel·la, hi ha una figura femenina amb la palma del martiri que, pel que sabem, no ha estat identificada. ${ }^{32}$

Com hem vist, en l'imaginari popular, amb el nom de Cebrià hi anava unit sovint el nom de Justina. Ho veiem en els goigs de sant Cebrià de Mollet d'Empordà i en la documentació que es conserva del seu retaule, que permet

\footnotetext{
30 Circulava una "Vida y martirio de los gloriosos san Cipriano y santa Justina», en quatre pàgines en vers, amb una imatge del martiri a la caldera, que relatava la conversió del bruixot, probablement a partir de la Llegenda Àuria. Era impresa a Barcelona, potser al segle XIX, i es pot consultar a: http://bibliotecadigital.jcyl.es/es/consulta/registro.cmd?id=6924 [data de consulta 20 d'octubre de 2019]. També a Barcelona fou impresa, el 1845, una «Oració dels gloriosos màrtirs sant Ciprià i santa Justina», que relatava la vida d'ambdós, en vers, amb un text diferent de la «Vida» castellana. Se'n conserva un exemplar a la biblioteca de l'IEC. Pere Anguera (2002: 47) fixa la versió castellana d'aquesta «Oració» el 1890. No es tracta de la mateixa «Oración de san Cipriano» impresa el 1631 i prohibida per la Inquisició, Itúrbide (2010). Aquestes oracions donen fe de la confusió popular entre el nom de Cebrià (fos quin fos) i el de Justina.

31 Aquesta vinculació del pretès sant Cebrià amb la màgia té sobretot difusió a Espanya, on hi ha tota una altra tradició, en part d'origen francès (grimoire), però també en part provinent de la mateixa llegenda grega, que es pot resseguir en el Ciprianillo i que no és objecte d'estudi aquí. Malgrat que Cebrià cremés tots els llibres de màgia, se li atribueixen popularment molts escrits posteriors vinculats amb les arts negres. Cf. Lafoz (1979) i Missler (2006).

32 Barrachina (2014:19).
} 
datar-lo el 1594. Segons la descripció detallada, el retaule tenia sant Cebrià al centre, una crucifixió a sobre i quatre camps amb la figura de sant Nicolau (i una escena de la seva vida), santa Justina i sant Miquel, dos profetes i dos patriarques, i sant Pere al sòcol. ${ }^{33}$

D'altra banda, el retaule de Sant Cebrià de Cabanyes, originari de sant Fost de Campsentelles, que actualment es conserva a la reserva del MNAC provinent d'una col·lecció privada, ${ }^{34}$ presenta sant Cebrià bisbe, al mig, amb quatre escenes de la vida i martiri del sant cartaginès.

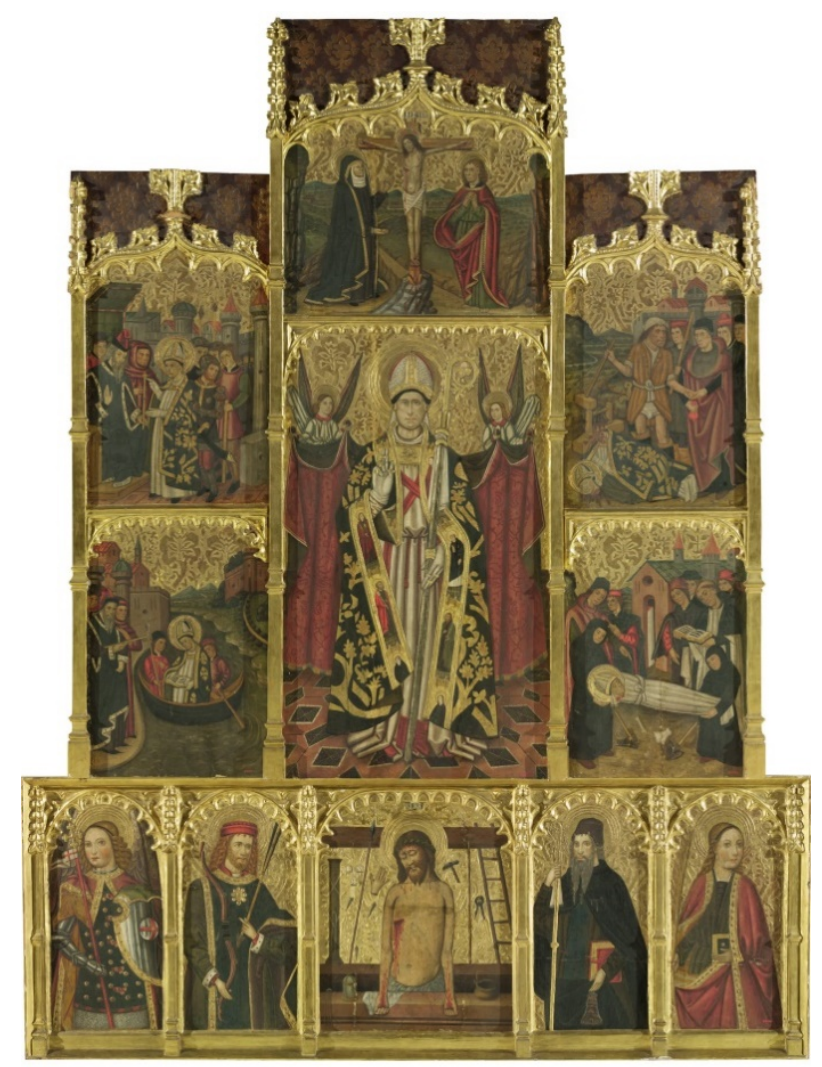

2. Retaule de sant Cebrià de Cabanyes. MNAC

Al centre de la predel-la hi ha Crist, i als costats hi ha sant Miquel, sant Sebastià, sant Antoni Abat, identificables tots pels atributs que els acompanyen, i una santa amb la palma del martiri, fins ara sense nom. Sant Miquel, sant Sebastià i sant Antoni Abat tenen una llarga tradició de culte i protecció a Catalunya, i no és estrany veure'ls al retaule, com tampoc no ho és trobar sant Nicolau al retaule de Mollet d'Empordà, on també hi ha sant Miquel.

33 Serna-Serra (2000: 215-6) i Moret-Serna (19).

${ }^{34}$ Adquisició de la col-lecció Muntades 1956. És atribuït al cercle de Jaume Huguet. El número de catàleg del MNAC és el 06406 3-CJT i la fotografia ha estat treta de la web del museu, www.museunacional.cat. 
La quarta figura, en canvi, posa dubtes. La proposta que fa Barrachina ${ }^{35}$ d'identificar-la com a santa Caterina pel llibre que porta no ens sembla gens probable. No pot ser Caterina d'Alexandria, perquè tindria com a atribut característic la roda del turment. Si porta un llibre, hauria de ser Caterina de Siena, que visqué al s. XIII, i que no era màrtir. ${ }^{36}$

No hi ha cap noia ni cap dona casada màrtir relacionada amb el bisbe de Cartago, en canvi, santa Justina sempre va acompanyada, en la tradició, del màrtir Cebrià, i gaudia d'una certa popularitat en la tradició catalana des del segle XI. Probablement, devia haver-hi una llegenda negra, almenys oral, fins i tot en els relats més inequívocament referits al cartaginès, com veiem en alguns goigs.

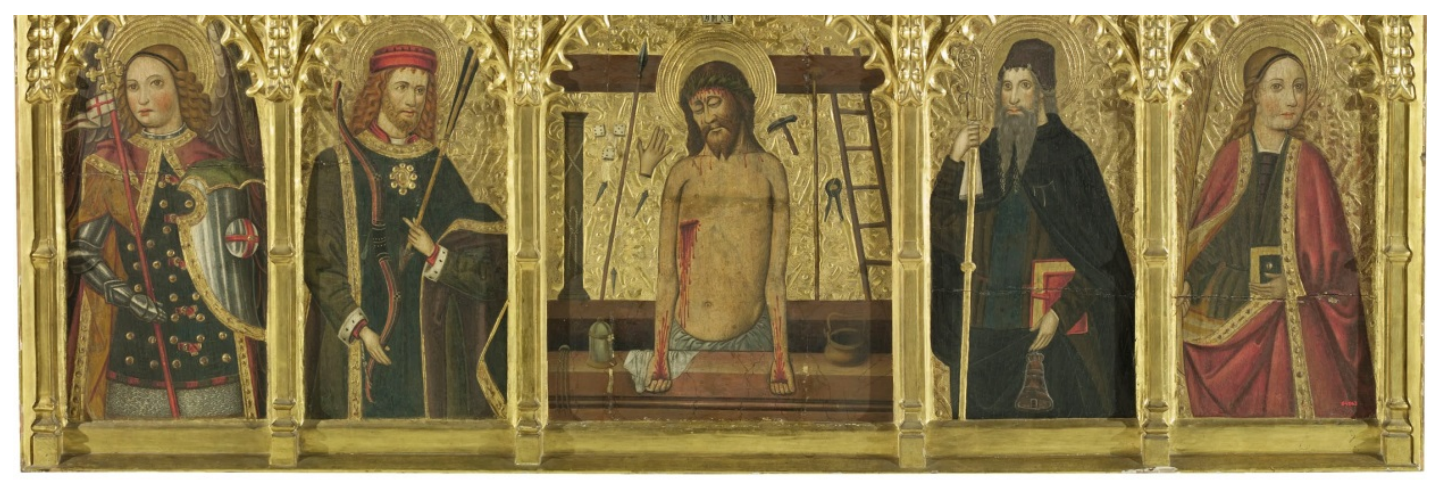

3. Predel-la del retaule de Cabanyes. D'esquerra a dreta, sant Miquel, sant Sebastià, el Crist, sant Antoni i una santa màrtir, potser santa Justina

Proposem que la figura femenina de la dreta de la predel-la sigui la màrtir Justina, és a dir, santa Justina de Pàdua, la qual és convencionalment representada amb la palma del martiri i un llibre. ${ }^{37} \mathrm{El}$ paral-lel amb el retaule de Mollet d'Empordà, uns cent anys posterior, que inclou explícitament la santa, serveix per donar suport a la hipòtesi.

\section{LA TRANSFORMACIÓ DE LA TRADICIÓ}

Pel que fa a l'ermita barcelonina de sant Cebrià d'Horta, continua sent lloc de trobada popular del barri. La cultura festiva i lúdica del segle XXI, que ha oblidat les velles tradicions hagiogràfiques cristianes, ha creat dos gegants que duen el nom de Cebrià i Justina, i que es passegen airosos i riallers el dia de la festa del

35 (2014: 20). Explica llargament l'origen del retaule i les peripècies de la identificació, així com la descripció documentada de les figures.

${ }^{36}$ Fou canonitzada el $1461 \mathrm{i}$ la festivitat no entrà a la litúrgia fins molt més endavant. Barrachina data el retaule cap al 1490, no és fàcil pensar que la veneració d'una santa italiana recent s'hagués escampat tan de pressa per Catalunya, però sobretot no li escau la palma del martiri. ${ }^{37}$ Ja hem esmentat l'origen de la tradició de Justina de Pàdua. És freqüent representar-la amb un llibre i la palma del martiri, un exemple evident n'és la pintura d'Andrea Mantegna. 
26 de setembre, ben lluny de les històries diabòliques dels seus inicis grecs al segle IV. ${ }^{38}$ Cebrià és caracteritzat de cavaller, amb un escut on hi ha gravada la figura de l'ermita, i Justina porta un porcell de senglar. En una societat que ha sofert un fort procés de secularització, les referències antigues es confonen amb la imatge del protector medieval (el model per excel-lència del qual és sant Jordi) $\mathrm{i}$ incorporen els neguits contemporanis, com l'animal que ha envaït Collserola. És la recepció última de la tradició.

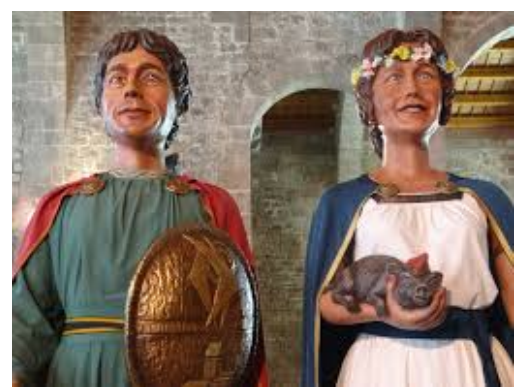

4. Gegants de Montbau, Cebrià i Justina (2011)

\section{BIBLIOGRAFÍA}

AMADES, J. (1983² [1956]), Costumari Català, vol. 5, Barcelona, Salvat-Edicions 62.

AmAdes, J., MALlafré, C., FABre, J. I Huertas Claveria, J. M. (1984), Històries i llegendes de Barcelona. Passejada pels carrers de la ciutat vella, Barcelona, Edicions 62.

ANGUERA, P. (2002), «Els usos del català a Catalunya al s. XIX», a Bernat Baldoví i el seu temps, Nicolàs, M., Valencia, Universitat de València.

BADIA, J. (1983), «Notícies sobre restes d'esglésies romàniques descobertes al Baix Empordà», Estudis del Baix Empordà, 2, 61-80.

BAILEY, R. (2009), The Confession of Cyprian of Antioch: Introduction, Text and Translation, thesis Master of Arts, Montreal, McGill University.

BARRACHINA J. (2014), «L'origen del retaule de Sant Cebrià de Cabanyes del Museu Nacional d'Art de Catalunya», Campsentelles, 17, Centre d'Estudis Santfostencs, 920.

BlÁZQUEZ, J. M. (1986), «La Carta 67 de Cipriano y el origen africano del cristianismo hispano», a Obras completas, Blázquez, J. M., Real Academia de la Historia, Madrid, 93-102.

CAMPS-GASET, M. (2019), «Black Magic and Christian Myth: a Covenant with the Devil in the $4^{\text {th }}$ century», a Pietat, prodigi i mitificació a la tradició literària occidental, Pomer J. J. i Redondo, J. (eds.) Amsterdam, Hakkert.

CANETTI, L. (2009), «Culti femminili nell'antica provincia eccleisastica ravennate: il caso di santa Giustina a Piacenza», a Giustina e le altre. Sante e culti femminile in Italia

38 Disponible a: https://commons.wikimedia.org/wiki/File:Gegants_al_Museu_Mar\%C3\%A Dtim_-_71_Gegants_de_Montbau_-_Cebri\%C3\%A0_i_Justina.JPG i https://www.lavanguardia .com/local/barcelona/20171217/433625508248/ermita-sant-cebria-montbau-barcelonasecreta.html [data de consulta: 1 novembre 2019]. 
settentrionale dalla prima età cristiana al secolo XII, Tilatti, A. i Trolese, F. (eds.), Atti del VI Convegno di Studio dell'A.I.S.S.C.A. 2004, Roma, Viella, 125-161.

Delehaye, H. (1931), «Cyprien d'Antioche et Cyprien de Carthage», Analecta Bollandiana 39, 314-322.

DÍAZ Y DÍAZ, M. (1998), «El culto de san Cipriano en Hispania», a Pensamiento medieval hispano, Soto Rábanos, J. M. (coord.), vol. 1., Madrid, CSIC, 21-38.

FÁbregA, A. (1953), Pasionario Hispánico (siglos VII-XI), Tomo I. Estudio. Tomo II. Texto, Madrid-Barcelona, CSIC.

ITÚRBIDE, J. (2010), «Piedad popular, exorcismes y censura inquisitorial. La Oración de san Cipriano impresa hacia 1631», Huarte de san Juan, Geografía e Historia 17, 333345.

LAFOZ, H. (1979), «El libro de san Cipriano en la Ribagorza, Sobrarbe y Somontano», I Congreso de Aragón de Etnología y Antropología (IHE 92-186), Zaragoza, 67-71.

LivreA, E. (1998), «L'imperatrice Eudocia e Roma. Per una datazione del de S. Cypr», Byzantinische Zeitschrift, 91, 70-91.

MADurell, J. M. (1948), «Sant Cebrià de Horta», Barcelona. Divulgación històrica, 5(53), 161-165.

MAdurell, J. M. (1960), «L'ermita de sant Cebrià i santa Justina», El Apostolado Franciscano, 51, 32-33.

MagGiOnI, G. P. (ed.) (1998), Iacopo da Varazze, Legenda Aurea, vol. 2, Florencia, Sismel. edicioni del Galluzo.

MAGGIONI, G. P. (ed.) (2013), Jean de Mailly. Abbreviatio in gestis et miraculis sanctorum: supplementum hagiographicum: editio princeps, Florencia, Sismel. edicioni del Galluzzo.

MissLeR, P. (2006), «Las hondas raíces del Ciprianillo, 2ª parte, los grimorios», Culturas Populares. Revista Electrónica, 3, septiembre-diciembre. Disponible a: $<$ http://www.culturaspopulares.org/textos3/articulos/missler.pdf $>$.

Montsalvatje, F. (1908), Nomenclator histórico de las iglesias parroquiales y rurales, santuarios y capillas de la provincia y obispado de Girona, Olot, Impr. J. Bonet.

Moret, R. M. I SernA, E. (2009), Mollet de Peralada, Quaderns de la Revista de Girona, 146, Girona, Diputació de Girona.

NILSSON, M. (1947), «Greek Mysteries in the Confession of St. Cyprian», Harvard Theological Review, 40(3), 167-176.

ORDEIG, R. (1991), «Inventari de les actes de consagració i dotació de les esglésies catalanes VII. Anys 1151-1200», RCatT, 16(2), 349-382.

PALMER, P. M. I MORE, R. P. (1936), The Sources of the Faust Tradition from Simon Magus to Lessing, Nova York, Oxford University Press.

Petruccione, J. (1990), «Prudentius' Portrait of St. Cyprian. An Idealized Biography», Revue des Études Augustiniennes, 36, 225-241.

RADERMACHER, L. (1927), «Griechische Quellen zur Faustsage», Sitzungsberichte der Akad. der Wiss. in Wien, 206(4), Leipzig-Viena, Hölder-Piehler Tempsky.

RAMOS Lissón, D. (2012), «EL culto a san Cipriano. Aproximación histórico-teológica a la eucología hispana», Theologica 2a S., 47(2), 439-454.

RIBAS, M. (1985), «El temple de santa Margarida de Cabrera de Mar. Casa de deodates», Sessió d'Estudis Mataronins, 2, 33-42.

SAbattinI, T. A. (1973), «S. Cipriano nella Tradizione Agiografica», Revista di Studi Classici, 21, 181-204. 
SERNA, E. I SERRA, J. (2000), «Documents per a la història de l'art altempordanès (15941618)», Annals de l'Institut d'Estudis Empordanesos, 33, 193-248.

Veronese, M. (2006), «La fama di Cipriano di Cartagine in Oriente», Studia Antiqua et Archaeologica, 7, 77-94.

ZAHN, TH. (1882), Cyprian von Antiochien und die deutsche Faustsage, Erlangen, A. Deichert Verlag.

ZARAGOZA, E. (1977), Catàleg dels monestirs catalans, Barcelona, Publicacions Abadia de Montserrat. 